\title{
Predictors of Intensive Care Unit admission in patients with coronavirus disease 2019 (COVID-19)
}

\author{
Maria Viviana Carlino, Natja Valenti, Flavio Cesaro, Anita Costanzo, Giovanna Cristiano, \\ Mario Guarino, Alfonso Sforza
}

Emergency Department, C.T.O. Hospital, Naples, Italy

\begin{abstract}
Italy is currently experiencing an epidemic of coronavirus disease 2019 (Covid-19). Aim of our study is to identify the best predictors of Intensive Care Unit (ICU) admission in patients with Covid-19. We examined 28 patients admitted to the Emergency Department (ED) and subsequently confirmed as cases of Covid-
\end{abstract}

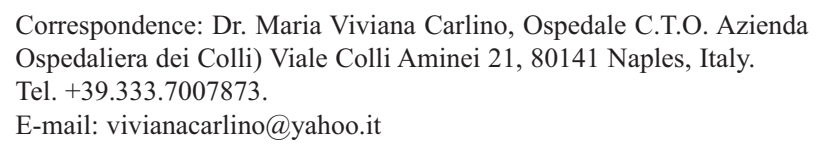

E-mail: vivianacarlino@yahoo.it

Key words: arterial blood gas analysis; alveolar-arterial oxygen gradient; hypoxemia; dyspnea; lactate.

Acknowledgments: We thank all the members of the C.T.O. Emergency Department. This article is dedicated to Antonio Sforza who is source of joy and inspiration for his parents.

Contributions: AS, MVC, conceived the paper and wrote the manuscript; NV, FC, AC, GC, MG, contributed to the discussion and edited the manuscript. All the authors have read and approved the final version of the manuscript and agreed to be accountable for all aspects of the work.

Conflict of interest: The authors declare that they have no competing interests, and all authors confirm accuracy.

Availability of data and materials: All data generated or analyzed during this study are included in this published article.

Ethics approval: All procedures performed in studies involving human participants were in accordance with the 1964 Helsinki declaration and its latest amendments.

Patient consent for publication: Not applicable.

Received for publication: 24 May 2020.

Accepted for publication: 8 July 2020.

${ }^{\circ}$ Copyright: the Author(s), 2020

Licensee PAGEPress, Italy

Monaldi Archives for Chest Disease 2020; 90:1410

doi: $10.4081 /$ monaldi.2020.1410

This article is distributed under the terms of the Creative Commons Attribution Noncommercial License (by-nc 4.0) which permits any noncommercial use, distribution, and reproduction in any medium, provided the original author(s) and source are credited.
19. Patients received, at the admission to the ED, a diagnostic work-up including: patient history, clinical examination, an arterial blood gas analysis (whenever possible performed on room air), laboratory blood tests, including serum concentrations of interleukin 6 (IL-6), lung ultrasound examination and a computed tomography (CT) scan of the thorax. For each patient, as gas exchange index through the alveolocapillary membrane, we determined the alveolar-arterial oxygen gradient $\left(\mathrm{AaDO}_{2}\right)$ and the alveolar-arterial oxygen gradient augmentation $\left(\mathrm{AaDO}_{2}\right.$ augmentation). For each patient, as measurement of hypoxemia, we determined oxygen saturation $\left(\mathrm{SpO}_{2}\right)$, partial pressure of oxygen in arterial blood $\left(\mathrm{PaO}_{2}\right), \mathrm{PaO}_{2}$ deficit and the ratio between arterial partial pressure of oxygen by blood gas analysis and fraction of inspired oxygen $(\mathrm{P} / \mathrm{F})$. Patients were assigned to ICU Group or to Non-ICU Group basing on the decision to intubate. Areas under the curve (AUC) and receiver operating characteristic (ROC) curve were used to compare the performance of each test in relation to prediction of ICU admission. Comparing patients of ICU Group (10 patients) with patients of Non-ICU Group (18 patients), we found that the first were older, they had more frequently a medical history of malignancy and they were more frequently admitted to ED for dyspnea. Patients of ICU Group had lower oxygen saturation, $\mathrm{PaO} 2, \mathrm{P} / \mathrm{F}$ and higher heart rate, respiratory rate, $\mathrm{AaDO} 2, \mathrm{AaDO} 2$ augmentation and lactate than patients of Non-ICU Group. ROC curves demonstrate that age, heart rate, respiratory rate, dyspnea, lactate, $\mathrm{AaDO}_{2}, \mathrm{AaDO}_{2}$ augmentation, white blood cell count, neutrophil count and percentage, fibrinogen, C-reactive protein, lactate dehydrogenase, glucose level, international normalized ratio (INR), blood urea and IL-6 are useful predictors of ICU admission. We identified several predictors of ICU admission in patients with Covid-19. They can act as fast tools for the early identification and timely treatment of critical cases since their arrival in the ED.

\section{Introduction}

A novel beta coronavirus $(2019-\mathrm{nCoV})$ was identified in a cluster of hospitalized patients with pneumonia of unknown cause in Wuhan, China, in December 2019 and January 2020 [1]. The pathogen was named severe acute respiratory syndrome coronavirus 2 (SARS-CoV-2) considering its phylogenetic similarity to SARS-CoV [1]. The World Health Organization (WHO) declared coronavirus disease 2019 (Covid-19) a public health emergency of international concern [2]. Covid-19 has spread rapidly throughout China causing a wide spectrum of clinical pictures [3]. Italy is currently experiencing an epidemic of Covid-19 which emerged in the region of Lombardy [4], progressing rapidly in all the country. 
Covid-19 caused thousands of deaths and stressed national health system, especially with regard to Intensive Care Units (ICU) [5]. Nowadays little evidence exists about the predictors of ICU admission in patients with Covid-19, in fact only clinical features and laboratory parameters have been evaluated. A recent retrospective case series of 1591 critically ill patients with laboratory-confirmed Covid-19 admitted to ICUs in Lombardy (Italy), showed as the majority were older men [6]. Many laboratory abnormalities (increased white blood cell count, neutrophil count, lactate dehydrogenase, alanine aminotransferase, aspartate aminotransferase, total bilirubin, creatinine, cardiac troponin, D-dimer, prothrombin time, procalcitonin and C-reactive protein, decreased lymphocyte count and albumin) were cited as predictive of adverse outcome in patients with Covid-19 [7]. There are no studies about the prognostic utility of arterial blood gas analysis in patients with Covid-19. The aim of our study is to evaluate clinical features, laboratory parameters and arterial blood gas analysis variables, identifying the best predictors of ICU admission in patients with Covid-19.

\section{Materials and Methods}

This observational study was conducted in the Emergency Department (ED) of C.T.O. Hospital in Naples (Italy) from 11 March 2020 to 25 April 2020. Our research satisfies the Helsinki criteria. We examined 28 consecutive patients admitted to the ED for respiratory symptoms (cough, fever, dyspnea) or syncope or chest pain or headache or myalgia or gastrointestinal symptoms (nausea, vomiting, diarrhea, and abdominal pain or discomfort) [8] and subsequently confirmed as cases of Covid-19 using real-time reverse-transcription Polymerase chain reaction (RT-PCR) assay of nasal and pharyngeal swab specimens, only laboratory-confirmed cases were included in the analysis. All patients have been clinically followed for at least 30 days from their admission to the ED. Patients received, at the admission to the ED, a diagnostic work-up including: patient history, clinical examination, an arterial blood gas analysis (whenever possible performed on room air), laboratory blood tests including serum concentrations of Interleukin 6 (IL-6), lung ultrasound examination and a computed tomography (CT) scan of the thorax. Laboratory blood tests and lung ultrasound examination data have been collected within $1 \mathrm{~h}$ from the arrival of the patients at the ED. For each patient, as gas exchange index through the alveolocapillary membrane, we determined the alveolar-arterial oxygen gradient $\left(\mathrm{AaDO}_{2}\right)$ [9] and the alveolar-arterial oxygen gradient augmentation $\left(\mathrm{AaDO}_{2}\right.$ augmentation) (Box 1). Measurements of arterial blood gases were obtained while the patient breathed room air. Using the estimated normal gradient [10] we calculated the alveolar-arterial oxygen gradient augmentation (Box 1) [11].

For each patient, as measurement of hypoxemia [12], we determined oxygen saturation $\left(\mathrm{SpO}_{2}\right), \mathrm{PaO}_{2}, \mathrm{PaO}_{2}$ deficit (11) [13] and $\left(\mathrm{PaO}_{2}\right) / \mathrm{FiO}_{2}$ or $\mathrm{P} / \mathrm{F}$ (Box 1). Based on the decision to intubate and the consequently ICU admission, the 28 patients were assigned to the ICU Group (ICUG) (10 patients) or to the Non-ICU Group (NICUG) (18 patients). Endotracheal intubation was performed for patients with $\mathrm{PaO}_{2} / \mathrm{FiO}_{2} \leq 150 \mathrm{mmHg}$ [14] and in case of failure to reach the established targets $\left(\mathrm{SpO}_{2} \geq 94 \%\right.$ and a respiratory rate $\leq 25$ breaths $/ \mathrm{min}$ ) after $120 \mathrm{~min}$ of continuous positive airways pressure (CPAP) [15]. Data were analyzed using SPSS version 21.0 (SPSS, Chicago, IL, USA). Continuous data are expressed as mean \pm 1 standard deviation and categorical variables as percentages. Quantitative variables were compared by using Student's $t$ test while chi-square distribution was used to compare categorical variables. A p-value $<0.05$ was considered statistically significant. Areas Under the Curve (AUC) and Receiver Operating Characteristic (ROC) curve were used to compare the performance of each different test in relation to the prediction of ICU admission. The Logistic Regression Analysis was used to evaluate which variables are the most powerful to predict the ICU admission.

\section{Results}

Our study population included 28 patients (16 males) with a mean age of 56 years. The symptoms at onset of illness were fever (57\%), dyspnea (32\%), gastrointestinal symptoms (14\%), cough $(11 \%)$, myalgia $(7 \%)$, headache $(7 \%)$, syncope $(7 \%)$, chest pain (7\%). Considering the 10 ICU patients, one was directly treated with the endotracheal intubation, while the other 9 patients were treated with continuous positive airways pressure (CPAP) for at least $120 \mathrm{~min}$ (the mean of the Positive End-Expiratory Pressure, PEEP) used was $9,67 \mathrm{cmH}_{2} \mathrm{O}$ while the mean of fraction of

\section{Box 1.}

The alveolar-arterial oxygen gradient was calculated as follows:

$\mathrm{AaDO}_{2}$ (mmHg), 150 - (1.25 x $\left.\mathrm{PaCO}_{2}\right)-\mathrm{PaO}_{2}$,

where $\mathrm{PaCO}_{2}$ is the partial pressure of carbon dioxide in arterial blood (mmHg) and $\mathrm{PaO}_{2}$ is the partial pressure of oxygen in arterial blood (mmHg).

Measurements of arterial blood gases were obtained while the patient breathed room air. The estimated normal gradient (mmHg) was calculated as follows:

$($ Age/4) +4

The alveolar-arterial oxygen gradient augmentation was calculated as follows:

$\mathrm{AaDO}_{2}$ augmentation (mmHg), $\mathrm{AaDO}_{2}$ - estimated normal gradient.

Owing to the natural decline in normal arterial oxygen levels with age, the estimated normal $\mathrm{PaO}_{2}(\mathrm{mmHg})$ was calculated as follows: 100 - Age/3.

The $\mathrm{PaO}_{2}$ deficit was calculated as follows:

$\mathrm{PaO}_{2}$ deficit (mmHg), estimated normal $\mathrm{PaO}_{2}$ - arterial blood gas analysis $\mathrm{PaO}_{2}$.

The $\mathrm{P} / \mathrm{F}$ was calculated as the ratio between arterial partial pressure of oxygen by blood gas analysis (in $\mathrm{mmHg}$ ) and fraction of inspired oxygen. 
inspired oxygen $\left(\mathrm{FiO}_{2}\right)$ was 95,55\%) before the endotracheal intubation that was performed because CPAP treatment failed to reach the established targets $\left(\mathrm{SpO}_{2} \geq 94 \%\right.$ and a respiratory rate $\leq 25$ breaths/min). Considering the 18 Non-ICU patients, 12 patients didn't require oxygen supplementation, 2 patients were treated with conventional nasal cannula (mean of $\mathrm{FiO}_{2}$ was $28 \%$ ), 1 patient was treated with Venturi mask $\left(\mathrm{FiO}_{2}\right.$ was $\left.60 \%\right)$ and the last 3 patients were treated with CPAP (the mean of PEEP used was 10 $\mathrm{cmH}_{2} \mathrm{O}$ while the mean of $\mathrm{FiO}_{2}$ was $50 \%$ ).

The baseline characteristics and the laboratory findings at the admission to the ED of the two subgroups are detailed in Table 1 and in Table 2, respectively. Comparing patients of the ICU Group with patients of the Non-ICU Group, the first were older, they had more frequently medical history of malignancy and they were more frequently admitted to the ED for dyspnea (Table 1, all $\mathrm{p}<0.05$ ). Patients of the ICU Group had lower oxygen saturation, $\mathrm{PaO}_{2}, \mathrm{PaCO}_{2}, \mathrm{P} / \mathrm{F}$ and higher heart rate, respiratory rate, AaDO2, $\mathrm{AaDO} 2$ augmentation and lactate levels than patients of the NonICU Group (Table 1, all $\mathrm{p}<0.05$ ). Considering laboratory findings, at the admission to the ED, patients of the ICU Group had lower lymphocyte count, lymphocyte percentage, monocyte percentage, albumin level and higher white blood cell count, neutrophil count, neutrophil percentage, C-reactive protein, INR, fibrinogen, lactate dehydrogenase, blood urea, glucose, Interleukin 6 than patients of the Non-ICU Group (Table 2, all p<0.05).

The receiver operating characteristic curve of epidemiological characteristics, medical history, vital signs and symptoms (Figure 1) demonstrates that age, heart rate, respiratory rate and dyspnea are useful in predicting ICU admission, while testing the ability to predict ICU admission of medical history of malignancy, it showed an AUC of 0.611. The receiver operating characteristic curve of arterial blood gas analysis parameters (Figure 2) demonstrates that lactate levels, $\mathrm{AaDO}_{2}$ and $\mathrm{AaDO}_{2}$ augmentation are useful in predicting ICU admission. The receiver operating characteristic curve of laboratory findings at the admission to the ED (Figure 3) demonstrates that INR, lactate dehydrogenase (LDH), blood urea, C-reactive protein, fibrinogen, neutrophil percentage, Interleukin 6 , neutrophil count, glucose and white blood cell count are useful in predicting ICU admission, while testing the ability to predict ICU admission of lymphocyte count, monocyte percentage, albu-

Table 1. Baseline characteristics at the admission to the Emergency Department of the two subgroups.

\begin{tabular}{|c|c|c|c|}
\hline & ICUG $(n=10)$ & NICUG $(n=18)$ & p \\
\hline Age (years) & $73 \pm 7.44$ & $47 \pm 12.62$ & 0.000 \\
\hline Sex (female) & $20 \%$ & $55 \%$ & 0.073 \\
\hline Medical history of arterial hypertension & $40 \%$ & $17 \%$ & 0.130 \\
\hline Medical history of chronic obstructivepulmonary disease or asthma & $30 \%$ & $22 \%$ & 0.553 \\
\hline Medical history of diabetes & $20 \%$ & $5 \%$ & 0.209 \\
\hline Medical history of malignancy & $20 \%$ & $0 \%$ & 0.039 \\
\hline Medical history of atrial fibrillation & $10 \%$ & $5 \%$ & 0.620 \\
\hline Medical history of ischemic heart disease & $30 \%$ & $5 \%$ & 0.059 \\
\hline Fever & $70 \%$ & $50 \%$ & 0.323 \\
\hline Dyspnea & $70 \%$ & $11 \%$ & 0.001 \\
\hline Gastrointestinal symptoms & $10 \%$ & $17 \%$ & 0.644 \\
\hline Cough & $0 \%$ & $17 \%$ & 0.185 \\
\hline Myalgia & $0 \%$ & $11 \%$ & 0.291 \\
\hline Headache & $0 \%$ & $11 \%$ & 0.291 \\
\hline Syncope & $10 \%$ & $5 \%$ & 0.676 \\
\hline Chest pain & $0 \%$ & $11 \%$ & 0.291 \\
\hline Systolic BP (mm Hg) & $130.1 \pm 30.9$ & $127.5 \pm 17.2$ & 0.776 \\
\hline Diastolic BP (mm Hg) & $76.7 \pm 14.79$ & $73.1 \pm 11.2$ & 0.476 \\
\hline Body temperature $\left({ }^{\circ} \mathrm{C}\right)$ & $36.1 \pm 1.0$ & $36.5 \pm 0.5$ & 0.220 \\
\hline Heart rate (bpm) & $91.4 \pm 17.9$ & $73.4 \pm 12.5$ & 0.004 \\
\hline Respiratory rate (breaths/min) & $24.4 \pm 7.7$ & $17.9 \pm 3.0$ & 0.005 \\
\hline Oxygen saturation (\%) & $86.9 \pm 11.7$ & $97.3 \pm 2.1$ & 0.001 \\
\hline $\mathrm{PaO}_{2}(\mathrm{mmHg})$ & $56.3 \pm 14.2$ & $78.3 \pm 10.0$ & 0.005 \\
\hline $\mathrm{PaCO}_{2}(\mathrm{mmHg})$ & $31.7 \pm 5.1$ & $37 \pm 5.8$ & 0.029 \\
\hline $\mathrm{PaO}_{2} / \mathrm{FiO}_{2}$ & $234.6 \pm 146.4$ & $362.7 \pm 59.9$ & 0.006 \\
\hline $\mathrm{PaO}_{2}$ deficit (mmHg) & $17.2 \pm 15.11$ & $6.3 \pm 7.8$ & 0.08 \\
\hline $\mathrm{pH}$ & $7.49 \pm 0.06$ & $7.45 \pm 0.06$ & 0.172 \\
\hline $\mathrm{AaDO}_{2}(\mathrm{mmHg})$ & $56.6 \pm 17.5$ & $25.9 \pm 9.7$ & 0.001 \\
\hline $\mathrm{AaDO}_{2}$ augmentation (mmHg) & $32.7 \pm 19.1$ & $10.3 \pm 8.00$ & 0.003 \\
\hline Lactate level $(\mathrm{mmol} / \mathrm{L})$ & $1.7 \pm 0.5$ & $0.7 \pm 0.2$ & 0.000 \\
\hline
\end{tabular}

ICUG, Intensive Care Unit Group; NICUG, Non- Intensive Care Unit Group; BP, blood pressure; $\mathrm{PaO}_{2}$, partial pressure of oxygen in arterial blood; $\mathrm{PaCO}_{2}$, partial pressure of carbon dioxide in arterial blood; $\mathrm{AaDO}_{2}$, alveolar-arterial oxygen gradient. 
Table 2. Laboratory findings at the admission to the Emergency Department of the two subgroups.

\begin{tabular}{|c|c|c|c|}
\hline & ICUG $(n=10)$ & NICUG $(n=18)$ & p \\
\hline White blood cell count $\left(\times 10^{3} / \mu \mathrm{L}\right)$ & $8.87 \pm 3.31$ & $5.11 \pm 1.41$ & 0.000 \\
\hline Neutrophil count $\left(\times 10^{3} / \mu \mathrm{L}\right)$ & $7.66 \pm 3.23$ & $3.24 \pm 1.36$ & 0.000 \\
\hline Neutrophil percentage & $85.34 \pm 5.68$ & $62.04 \pm 12.21$ & 0.000 \\
\hline Lymphocyte count $\left(\times 10^{3} / \mu \mathrm{L}\right)$ & $0.78 \pm 0.34$ & $1.39 \pm 0.57$ & 0.007 \\
\hline Lymphocyte percentage & $9.51 \pm 3.88$ & $28.10 \pm 10.28$ & 0.000 \\
\hline Eosinophil count $\left(\times 10^{3} / \mu \mathrm{L}\right)$ & $0.04 \pm 0.10$ & $0.06 \pm 0.12$ & 0.588 \\
\hline Eosinophil percentage & $0.30 \pm 0.71$ & $1.62 \pm 2.59$ & 0.149 \\
\hline Basophil count $\left(\times 10^{3} / \mu \mathrm{L}\right)$ & $0.02 \pm 0.01$ & $0.02 \pm 0.04$ & 0.744 \\
\hline Basophil percentage & $0.21 \pm 0.10$ & $0.32 \pm 0.23$ & 0.202 \\
\hline Monocyte count $\left(\times 10^{3} / \mu \mathrm{L}\right)$ & $0.36 \pm 0.19$ & $0.42 \pm 0.15$ & 0.365 \\
\hline Monocyte percentage & $4.62 \pm 2.55$ & $9.08 \pm 3.57$ & 0.003 \\
\hline C-reactive protein (mg/L) & $171.59 \pm 101.47$ & $20.55 \pm 38.14$ & 0.000 \\
\hline Procalcitonin $(\mu \mathrm{g} / \mathrm{L})$ & $2.30 \pm 5.98$ & $0.10 \pm 0.19$ & 0.125 \\
\hline INR & $1.42 \pm 0.25$ & $1.07 \pm 0.05$ & 0.000 \\
\hline D-dimer $(\mu \mathrm{g} / \mathrm{L})$ & $6227.60 \pm 17364.92$ & $268.22 \pm 323.75$ & 0.151 \\
\hline Fibrinogen (mg/dL) & $651.11 \pm 302.77$ & $363.55 \pm 125.75$ & 0.002 \\
\hline Lactate dehydrogenase (U/L) & $748.70 \pm 543.80$ & $189.94 \pm 51.89$ & 0.000 \\
\hline Albumin level (g/dL) & $3.45 \pm 0.36$ & $4.39 \pm 0.55$ & 0.000 \\
\hline Alanine aminotransferase (U/L) & $52.80 \pm 47.62$ & $28.89 \pm 17.2$ & 0.064 \\
\hline Serum creatinine (mg/dL) & $0.96 \pm 0.27$ & $0.85 \pm 0.22$ & 0.274 \\
\hline Blood urea (mg/dL) & $74.20 \pm 25.53$ & $34.61 \pm 8.27$ & 0.000 \\
\hline Sodium (mmol/L) & $136.70 \pm 4.22$ & $138.72 \pm 2.08$ & 0.099 \\
\hline Potassium (mmol/L) & $4.22 \pm 0.62$ & $4.02 \pm 0.36$ & 0.294 \\
\hline Glucose (mg/dL) & $145.10 \pm 44.07$ & $101.67 \pm 23.02$ & 0.002 \\
\hline Interleukin 6 (pg/mL) & $58.51 \pm 48.63$ & $14.03 \pm 19.21$ & 0.006 \\
\hline
\end{tabular}

ICUG, Intensive Care Unit Group; NICUG, non-ICU Group; INR, international normalized ratio.

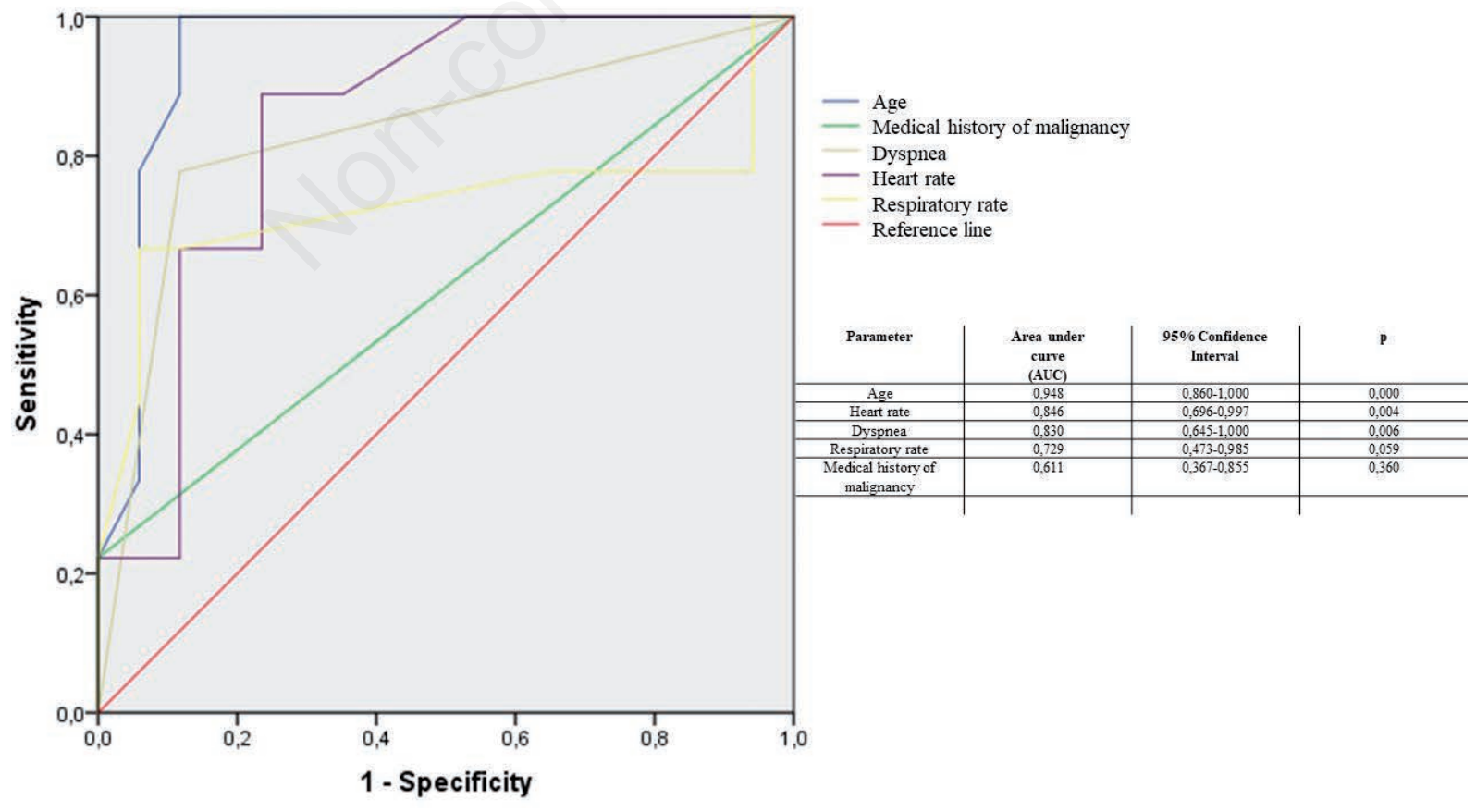

Figure 1. Receiver operating characteristic (ROC) curve comparing accuracy of epidemiological characteristics, medical history, vital signs and symptoms in relation to the prediction of ICU admission in patients with Covid-19. 
min and lymphocyte percentage, they showed an AUC of 0.2360.148-0.093-0.044, respectively. From the Logistic Regression Analysis we obtained the following two equations:

$$
\begin{gathered}
\mathrm{P}=1 / 1+\mathrm{e}^{-(-274.480+0.905 \times \text { lactate dehydrogenase })} \\
\mathrm{P}=1 / 1+\mathrm{e}^{-(-210.877+175.594 \times \text { lactate level })}
\end{gathered}
$$

This model allows $100 \%$ correct classification of patients into the two different groups. Critical values were $>303.29$ for lactate dehydrogenase and $>1.201$ for lactate level.

\section{Discussion}

Most patients with Covid-19 have mild symptoms, while some others may develop severe complications including Acute Respiratory Distress Syndrome (ARDS) and multi-organ failure leading to ICU admission and death. Emergency physicians should identify patients with severe symptoms, hypoxemia with the need for oxygen supplementation, or high risk for clinical deterioration that require admission for further management and monitoring [16]. In our study, among epidemiological characteristics, the best predictor of ICU admission in patients with Covid-19 was the age (AUC 0.948) as previously demonstrated by Wang et al. [17]. In our population there was not a good predictor of ICU admission among coexisting medical conditions, in fact medical history of malignancy was more frequent in the ICU Group than in the NonICU Group $(p<0.05)$ but it showed an AUC of just 0.611. Among symptoms at ED presentation, dyspnea was a good predictor of ICU admission showing an AUC of 0.830 , while among vital signs the best predictors were heart rate and respiratory rate (AUC $0.846-0.729$, respectively). These clinical findings are attributable to hypoxemia that represents the main pathophysiological complication of patients with pneumonia. In particular, the development of hypoxemia reflects the severity of lung involvement (interstitium inflammation and alteration of the alveolar ventilation) leading to intrapulmonary shunt in the affected zone [18]. Shunt is a condition whereby blood from the right side of the heart enters the left side without taking part in any gas exchange and it can be caused by pneumonia and ARDS [12]. There are different measurement of hypoxemia and among them, in our study, oxygen saturation, $\mathrm{PaO}_{2}$ and $\mathrm{P} / \mathrm{F}$ showed a statistically significant difference between the two groups (all $\mathrm{p}<0.05$ ), underlining the major grade of hypoxemia of the ICU group patients since their admission to the ED. The AaDO2 is an index of gas exchange and indicates the integrity of the alveolo-capillary membrane being influenced by diffusion gradient, ventilation-perfusion imbalance and true shunt [9]. In our study, ICU group patients had higher $\mathrm{AaDO}_{2}$ and $\mathrm{AaDO}_{2}$ augmentation than non-ICU group patients (all $\mathrm{p}<0.05)$ underlining the alveolo-capillary membrane damage and the consequent worsening of gas exchange in the ICU group since their admission to the Emergency Department. Furthermore, $\mathrm{AaDO}_{2}$ and $\mathrm{AaDO}_{2}$ augmentation showed an excellent and a good accuracy (AUC of 0.952 and 0.810 respectively) to predict ICU admission in patients with Covid-19 since their arrival in the Emergency Department. Among arterial blood gas analysis parameters, lactate level was higher in the ICU Group $(1.7 \pm 0.5 \mathrm{mmol} / \mathrm{L})$ than in the Non-ICU Group $(0.7 \pm 0.2 \mathrm{mmol} / \mathrm{L})$ with statistical significance. Furthermore lactate showed an excellent accuracy (AUC 1.000) to predict ICU admission, since it can be used as an early marker of reduced tissue oxygenation, organ failure and occult shock before any detectable changes occur in patients' vital signs [19].

White blood cell count, neutrophil count and neutrophil percentage were higher in the ICU Group than in the non-ICU Group with statistical significance and, in particular, neutrophil percentage

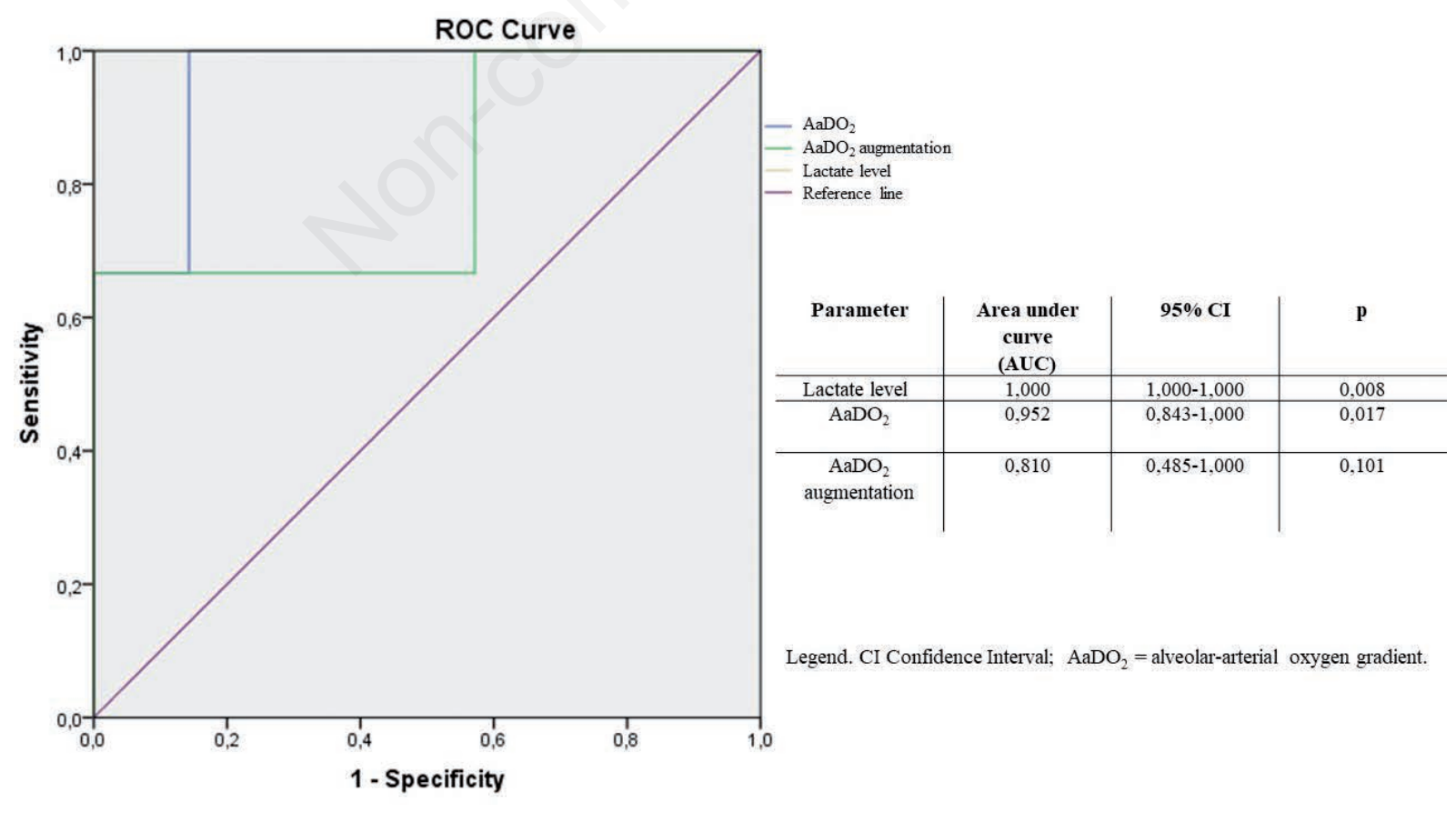

Figure 2. Receiver operating characteristic (ROC) curve comparing accuracy of arterial blood gas analysis parameters at the admission to the Emergency Department in relation to the prediction of ICU admission in patients with Covid-19. 
showed an excellent accuracy (AUC 0.954) and white blood cell count and neutrophil count a good accuracy (AUC 0.847 and 0.898 , respectively), to predict ICU admission in patients with Covid-19. This can be explained by the increased severity of Systemic Inflammatory Response Syndrome (SIRS) in the ICU patients compared to the Non-ICU patients and also by possible bacterial overinfections. Recently, Barnes et al. suggested that the severe symptoms of Covid-19, including ARDS, could be caused by Neutrophil Extracellular Traps (NETs), since they found lung infiltration of neutrophils in an autopsy specimen from a patient who succumbed to Covid-19 [20]. Lymphocyte count and lymphocyte percentage were reduced below the normal values in the majority of patients included in the study (2019-nCoV might mainly act on lymphocytes, especially T- lymphocytes, just like SARS-CoV [21]) and they were reduced more profoundly in the ICU Group than in the non-ICU Group (all $\mathrm{p}<0.05$ ), but they failed to predict ICU admission, AUC of 0.236 and 0.044 , respectively). In our study, the levels of non-specific inflammation parameters, such as fibrinogen, C-reactive protein and lactate dehydrogenase were higher in the ICU Group than in the non-ICU Group with statistical significance and they showed an excellent accuracy to predict ICU admission (AUC 0.959, 0.969 and 0.980 , respectively). Considering the inflammatory status, it is not surprising that in our study glucose level was significantly higher in the ICU Group than in the non-ICU Group and it showed a good accuracy (AUC 0.816) to predict ICU admission. Comparing the ICU Group with the non-ICU Group, we found in the first group higher international normalized ratio (INR) and lower albumin level indicating that critical patients developed liver failure besides the fact that the angiotensin-converting enzyme 2 (ACE 2), a key receptor for the SARS-CoV-2 viral entry, is also expressed by cholangiocytes in liver and enterocytes in intestine [22]. Furthermore, INR showed an excellent accuracy (AUC 1.000) to predict ICU admission. In our study, blood urea was significantly higher in the ICU
Group than in the non-ICU Group, showing an excellent accuracy (AUC 0.949) to predict ICU admission. This finding can be explained by the hypoperfusion-related injury of the renal tubules due to cytokine storm and also by the fact that podocytes and tubule epithelial cells express the ACE2 receptor [23]. Furthermore, the ICU patients are probably more dehydrated than the non-ICU patients. A large number of data suggest that cytokine storm, in critical patients with Covid-19, is an important cause of death [24]. Therefore, considering that interleukin-6 (IL-6) plays an important role in cytokine release syndrome, it is not surprising that in our study IL-6 was significantly higher in the ICU Group than in the non-ICU Group and that it showed an excellent accuracy (AUC $0.929)$ to predict ICU admission. Basing on the results of Logistic Regression Analysis, lactate dehydrogenase and lactate level seem to be the most powerful variables to predict the ICU admission. Probably the elevated serum LDH concentration in the ICU patients reflects cellular hypoxia and tissue necrosis, while the elevated lactate level can be due to hypoxia and to the high respiratory rate generating fatigue of the respiratory muscles.

The main limitation of our study is that the population sample could be larger, but considering that the pandemic had a limited extension in the south of Italy a group of only 28 patients could be representative of how this health emergency has been managed in a southern Italy hospital.

\section{Conclusions}

We identified several predictors of ICU admission in patients with Covid-19. They can act as fast tools for the early identification and timely treatment of critical cases since their arrival in the Emergency Department.
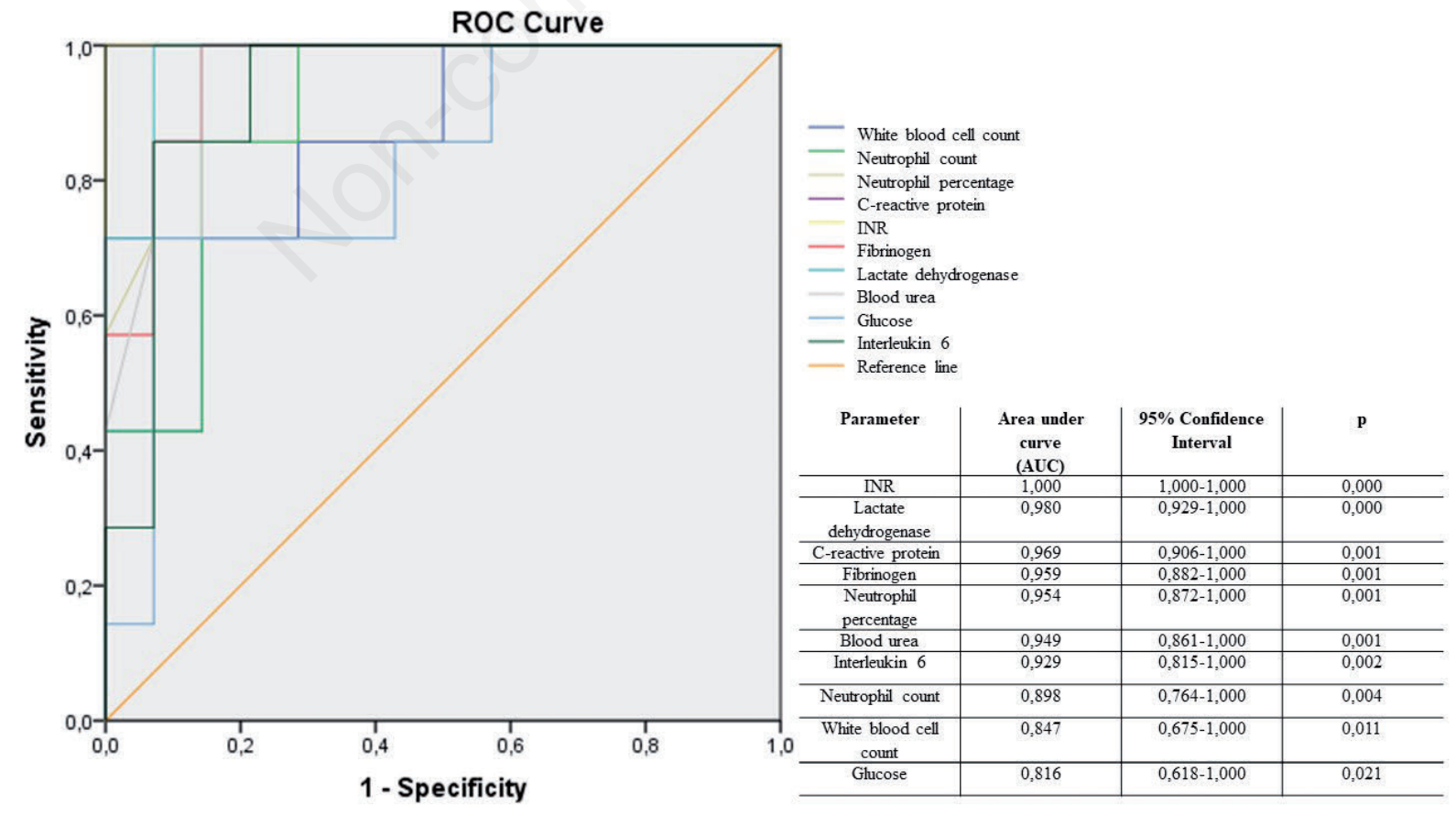

Figure 3. Receiver operating characteristic (ROC) curve comparing accuracy of laboratory findings at the admission to the Emergency Department in relation to the prediction of ICU admission in patients with Covid-19. 


\section{References}

1. Zhu N, Zhang D, Wang W, et al. A novel coronavirus from patients with pneumonia in China, 2019. China novel coronavirus investigating and research. N Engl J Med 2020;382: 727-33.

2. WHO. Coronavirus disease (COVID-19) outbreak. Available from: https://www.who.int

3. Guan WJ, Ni ZY, Hu Y et al. Clinical characteristics of coronavirus disease 2019 in China. N Engl J Med 2020;382:708-20.

4. Day M. Covid-19: Italy confirms 11 deaths as cases spread from north. BMJ 2020;368:m757.

5. Onder G, Rezza G, Brusaferro S. Case-Fatality rate and characteristics of patients dying in relation to COVID-19 in Italy. JAMA 2020. doi: 10.1001/jama.2020.4683.

6. Grasselli G, Zangrillo A, Zanella A, et al. Baseline characteristics and outcomes of 1591 patients infected with SARS-CoV-2 admitted to ICUs of the Lombardy region, Italy. JAMA 2020. doi: 10.1001/jama.2020.5394.

7. Lippi G, Plebani M. Laboratory abnormalities in patients with COVID-2019 infection. Clin Chem Lab Med 2020;58;1131-4.

8. Jin X, Lian JS, Hu JH, et al. Epidemiological, clinical and virological characteristics of 74 cases of coronavirus-infected disease 2019 (COVID-19) with gastrointestinal symptoms. Gut 2020. pii: gutjnl-2020-320926.

9. Hsu JT, Chu CM, Chang ST, et al.Prognostic role of alveolararterial oxygen pressure difference in acute pulmonary embolism. Circ J 2006;70:1611-6.

10. McFarlane MJ, Imperiale TF. Use of the alveolar-arterial oxygen gradient in the diagnosis of pulmonary embolism. Am J Med 1994;96:57-62.

11. Carlino MV, Guarino M, Izzo A, et al. Arterial blood gas analysis utility in predicting lung injury in blunt chest trauma. Respir Physiol Neurobiol 2020;274:103363.

12. Sarkar M, Niranjan N, Banyal PK. Mechanisms of hypoxemia. Lung India 2017;34:47-60.
13. O'Driscoll BR, Howard LS, Davison AG. BTS guideline for emergency oxygen use in adult. Thorax 2008;63:vi1-68.

14. Fan E, Brodie D, Slutsky AS. Acute respiratory distress syndrome: advances in diagnosis and treatment. JAMA 2018;319: 698-710.

15. Privitera D, Angaroni L, Capsoni N, et al. Flowchart for noninvasive ventilation support in COVID-19 patients from a northern Italy Emergency Department. Intern Emerg Med 2020;20:1-5.

16. Chavez S, Long B, Koyfman A, Liang SY. Coronavirus disease (COVID-19): A primer for emergency physicians. Am J Emerg Med 2020. doi: 10.1016/j.ajem.2020.03.036.

17. Wang D, Hu B, Hu C, et al. Clinical characteristics of 138 hospitalized patients with 2019 novel coronavirus-infected pneumonia in Wuhan, China. JAMA 2020;323:1061-9.

18. Sanz F, Restrepo MI, Fernandez E, et al. Is it possible to predict which patients with mild pneumonias will develop hypoxemia? Respir Med 2009;103:e1871-7.

19. Juneja D, Singh O, Dang R. Admission hyperlactatemia: causes, incidence, and impact on outcome of patients admitted in a general medical intensive care unit. J Crit Care 2011;2:316-20.

20. Barnes BJ, Adrover JM, Baxter-Stoltzfus A, et al. Targeting potential drivers of COVID-19: Neutrophil extracellular traps. J Exp Med 2020;217. pii: e20200652.

21. Chen N, Zhou M, Dong X, et al. Epidemiological and clinical characteristics of 99 cases of 2019 novel coronavirus pneumonia in Wuhan, China: a descriptive study. Lancet 2020;395: 507-13.

22. Sarin SK. Fast, faster, and fastest: science on the run during COVID-19 drama - do not forget the liver. Hepatol Int 2020. doi: 10.1007/s12072-020-10042-0.

23. Durvasula R, Wellington T, McNamara E, Watnick S. COVID19 and kidney failure in the acute care setting: our experience from Seattle. Am J Kidney Dis 2020;76:4-6.

24. Zhang C, Wu Z, Li JL, et al. Cytokine release syndrome (CRS) of severe COVID-19 and interleukin-6 receptor (IL-6R) antagonist tocilizumab may be the key to reduce the mortality. Int $\mathrm{J}$ Antimicrob Agents 2020;55:105954. 